\title{
CORRECTION
}

\section{Correction: Chemotherapy with radiotherapy influences time- to-development of radiation-induced sarcomas: a multicenter study}

A. Y. Zhang ${ }^{1,2}$, I. Judson ${ }^{3}$, C. Benson ${ }^{3}$, J. S. Wunder ${ }^{4,5}$, I. Ray-Coquard ${ }^{6}$, R. J. Grimer ${ }^{7}$, R. Quek ${ }^{8}$, E. Wong ${ }^{3}$, A. B. Miah ${ }^{3}$, P. C. Ferguson ${ }^{4,5}$, A. Dufresne ${ }^{6}$, J. Y. H. Teh ${ }^{8}$, M. Stockler ${ }^{2,9}$ and M. H. N. Tattersall ${ }^{1,2}$

British Journal of Cancer https://doi.org/10.1038/s41416-018-0079-9

Correction to: British Journal of Cancer (2017) 117, 326-331; https://doi.org/10.1038/bjc.2017.198; published online 27 June 2017

Since the publication of this paper, the authors noticed an error in Fig. 1. The $X$-axis on all the figure panels should read "Time (years)", not "Time (months)". The corrected Fig. 1 is shown below.

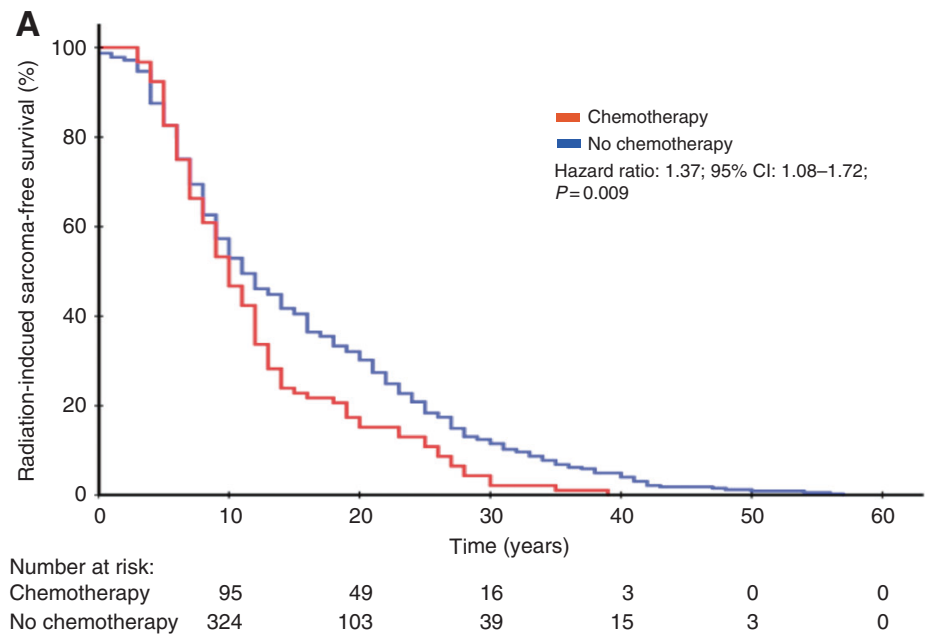

This error does not affect the conclusion of the paper, or any other section of the manuscript.

\section{ADDITIONAL INFORMATION}

Note: 'This work is published under the standard license to publish agreement. After 12 months the work will become freely available and the license terms will switch to a Creative Commons Attribution-NonCommercial-Share Alike 4.0 Unported License.

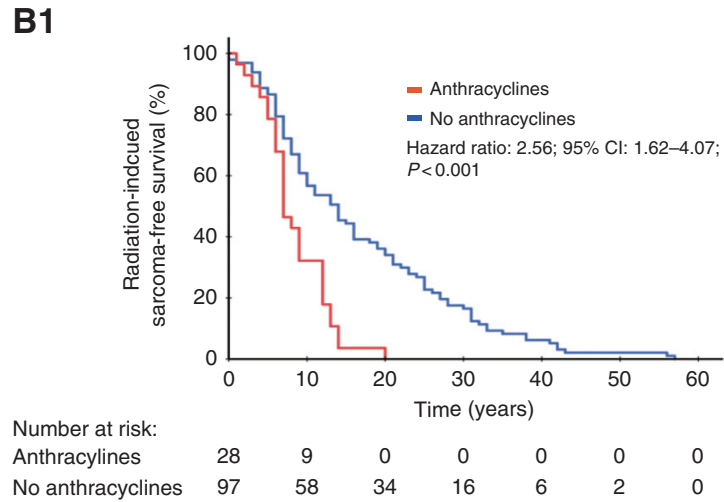

B2

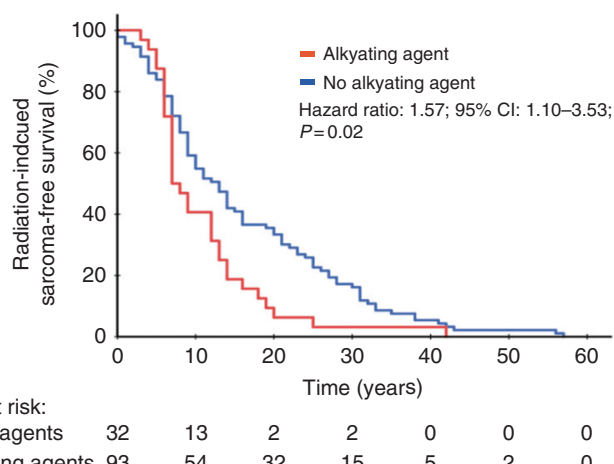

Fig. 1 a Kaplan-Meier estimates of radiation-induced sarcoma-free survival by chemotherapy use for all patients in the study cohort; $\mathbf{b}$ Kaplan-Meier estimates of radiation-induced sarcoma-free survival by (B1) anthracycline and (B2) alkylating chemotherapy use in the Léon Bérard and Mount Sinai Hospital cohorts

\footnotetext{
${ }^{1}$ The University of Sydney, Sydney 2006, Australia; ${ }^{2}$ Chris O'Brien Lifehouse, Sydney 2050, Australia; ${ }^{3}$ Royal Marsden NHS Foundation Trust, London SW3 6JJ, UK; ${ }^{4}$ Musculoskeletal Oncology Unit, Mount Sinai Hospital, Toronto, ON M5G 1X5, Canada; ${ }^{5}$ Department of Surgery, University of Toronto, Toronto, ON M5S, Canada; ${ }^{6}$ Centre Léon Bérard, University Claude Bernard, Lyon 69100, France; ${ }^{7}$ The Royal Orthopaedic Hospital NHS Trust, Birmingham B31 2AP, UK; ${ }^{8}$ National Cancer Centre, Singapore 169610 , Singapore and ${ }^{9}$ NHMRC Clinical Trials Centre, University of Sydney, Sydney 2006, Australia

Correspondence: A. Y. Zhang (alisonwestmead@gmail.com)
}

Published online: 29 May 2018 